\title{
A practical contemporary approach to decision-making on subclinical hypothyroidism
}

${ }^{1}$ Unidade de Tireoide, Divisão de Endocrinologia e Metabolismo, Faculdade de Medicina de Marília (Famema), Marília, SP, Brasil ${ }^{2}$ Laboratório de Genética Molecular do Câncer, Faculdade de Ciências Médicas (FCM), Universidade Estadual de Campinas (Unicamp), Campinas, SP, Brasil
Correspondence to: José Augusto Sgarbi Divisão de Endocrinologia e Metabolismo, Faculdade de Medicina de Marília (Famema)

Av. Monte Carmelo, 800

17519-030 - Marília, SP, Brasil

jose.sgarbi@gmail.com

Received on July/29/2020

Accepted on Oct/2/2020

DOI: 10.20945/2359-3997000000317
José Augusto Sgarbi ${ }^{1}$

https://orcid.org/0000-0001-7187-984X

Laura Sterian Ward ${ }^{2}$

https://orcid.org/0000-0003-1601-3220

\begin{abstract}
Subclinical hypothyroidism (Shypo) is an increasingly frequent condition in common medical practice. Its diagnosis continues to pose a challenge since a series of non-thyroidal and temporary conditions can elevate serumTSH levels. In addition, the consequences of Shypo are still up for debate. Although detrimental cardiovascular effects have been consistently demonstrated in the young, they are less evident in older adults (65-79 years), and even more so in the oldest old ( $\geq 80$ years). In the absence of evidence of any benefits of treating Shypo in patients' clinical manifestations and unfavorable outcomes, the most effective decision-making approach should include a thorough investigation of the patient's condition integrating all relevant clinical data, such as TSH levels, age, quality of life, comorbidities, cardiovascular risk, safety, and personal preferences. The decision-making process needs to take into account the risk of levothyroxine overtreatment and the resulting adverse consequences, such as reduction of bone mineral density, heart failure, and atrial fibrillation. Hence, current evidence suggests that individuals with TSH $>10 \mathrm{mU} / \mathrm{L}$, who test positive for TPO Ab or are symptomatic may benefit from levothyroxine treatment. However, a more cautious and conservative approach is required in older ( $\geq 65$ years of age), and oldest-old ( $\geq 80$ years) patients, particularly those with frailty, in which the risk of treatment can outweigh potential benefits. The latter may benefit from a wait-and-see approach. Arch Endocrinol Metab. 2021;65(1):32-9
\end{abstract}

Keywords

Subclinical hypothyroidism; thyrotropin; levothyroxine; update; treatment

\section{INTRODUCTION}

$\mathrm{M}$ anagement of subclinical hypothyroidism (Shypo), a condition biochemically defined by serum elevated thyroid-stimulating hormone (TSH) levels in the face of normal concentrations of free $\mathrm{T}_{4}(\mathrm{fT} 4)$, is one of the main challenges in current thyroid clinical practice (1-3). Shypo is the most frequent thyroid dysfunction in the general population, affecting up to $10 \%$ of iodinesufficient populations, and is more prevalent in women, in whites, and in elderly people (4). In North America (5), the prevalence of Shypo has been estimated between $4.3 \%$ and $9.5 \%$; in Europe, it is around 6.7\% (6); and in Latin America, Brazil has been considered to be the country with the greatest prevalence of Shypo (4), varying from $5.4 \%$ (7) to $9.0 \%(8)$.

Caution needs to be taken in the diagnostic and therapeutic management of patients. Of note, nonthyroidal causes of Shypo and transient elevation of TSH levels must be excluded before considering treating a patient (9-12). Over the last decades, a growing body of evidence has associated Shypo with dyslipidemia (13-15), coronary heart disease (CHD) $(16,17)$, stroke (18), and heart failure (HF) (19-21). However, despite advances in the knowledge of the clinical significance of Shypo, many uncertainties remain in practical management: it is usually an asymptomatic and frequently undiagnosed condition in the general population, and whether to screen individuals is still debated (22). Young and old are affected differently (23). Diagnostic criteria and therapeutic management of elderly patients are not clear (24). Moreover, no powered randomized clinical trial (RCT) has shown any clinical benefits from levothyroxine therapy, which remains controversial (22-28). Consequently, a series of factors need to be considered before deciding to treat or not a patient, including all the available evidence, clinical data, safety concerns, and patient preferences (29).

In this review, we summarize up-to-date information on the current evidence that can underpin the clinical management of patients with Shypo in adults (>18 
years of age), except pregnant women. We focused on Medline-PubMed English literature and Cochrane Library databases using the term "subclinical hypothyroidism" combined with "differential diagnosis", "natural history", "quality of life", cognitive symptoms", "depression", "dyslipidemia”, "cardiovascular disease", "heart failure", "stroke", "mortality", "age", "treatment", and "levothyroxine". We prioritized systematic reviews, meta-analyses, randomized-controlled clinical trials, and high-quality prospective observational studies. Guidelines and relevant reviews were also included.

\section{DIAGNOSIS}

Determination of serum TSH levels should be performed if hypothyroidism is suspected or as a casefinding strategy for specific high-risk groups of patients, such as women over 35 years of age, patients with a previous personal or family history of thyroid disease, type 1 diabetes, or other autoimmune diseases, Down and Turner syndromes, dyslipidemia, depression, or in patients using lithium or amiodarone (9-11). In addition, the Latin American Thyroid Society has proposed including both metabolic syndrome and type 2 diabetes patients among high-risk groups for hypothyroidism (30).

The diagnosis of Shypo can be confirmed by the presence of high serum TSH levels and normal fT4 concentrations (9-12). However, Shypo must be differentiated from other non-thyroidal causes of elevated serum TSH levels and normal fT4 concentrations, summarized in Table 1. Special attention should be paid to elevated TSH levels in the elderly, severely obese, critically ill, or hospitalized patients (3). The normal upper limit for TSH values may physiologically increase in healthy elderly people as a consequence of a reduced metabolic status or as an adaptive mechanism of protection against the catabolism of the aging process (24). Therefore, it is essential to differentiate the physiological increase of TSH levels from real thyroid dysfunction, bearing in mind that the diagnosis of Shypo should take into account the normal TSH reference ranges for the age (31). A Brazilian study suggested that TSH upper levels correspond to $4.3 \mathrm{mU} / \mathrm{L}$ for individuals between 20 and 59 years, $5.8 \mathrm{mU} / \mathrm{L}$ for those between 60 and 79 years, and $6.7 \mathrm{mU} / \mathrm{L}$ for those over 80 (32). It has been demonstrated that the prevalence of Shypo in patients with obesity is relatively high (33), but the diagnosis of Shypo may be complex in the severely obese, particularly with body mass index $\geq 40 \mathrm{~kg} / \mathrm{m}^{2}(3)$, since a slight increase in TSH levels (usually $<8 \mathrm{mU} / \mathrm{L}$ ) can occur as a consequence of the direct stimulatory effect of leptin on the hypothalamic neurons secreting the thyrotropin stimulating hormone $(34,35)$, which is not a true thyroid disease. Thus, in the case of a severely obese patient, the presence of positive TPOAb and TSH levels $\geq 10 \mathrm{mU} / \mathrm{L}$ suggests Shypo. Finally, in critically ill, hospitalized patients, alterations in thyroid function tests can be found without the presence of any thyroid disease (36). Serum TSH levels may increase during the recovery phase of acute illnesses, although levels usually do not exceed 20 $\mathrm{mU} / \mathrm{L}(9,12)$. Therefore, under such circumstances, denominated "euthyroid sick syndrome" or "nonthyroidal illness syndrome" (36), investigation of thyroid dysfunction should be avoided or requested only if there is strong suspicion of thyroid gland dysfunction $(9,12)$. Other less common non-thyroidal causes (Table 1) of increased serum TSH levels include artifactual assay interferences by heterophilic antibodies or macro TSH, untreated Addison's disease, and thyrotropin resistance by mutation of the TSHreceptor (1-3). Transient causes of raised TSH, listed

Table 1. Causes of elevated TSH and normal fT4 concentrations

\begin{tabular}{l}
\hline Thyroidal causes \\
\hline - Autoimmune thyroiditis (silent, post-partum and Hashimoto disease) \\
- Subacute and other forms of thyroiditis \\
- Thyroid lobectomy \\
- Post radioiodine therapy to treat Graves' disease \\
- Post external radiotherapy of the cervical region \\
- Inadequate treatment of overt hypothyroidism \\
- Drug-induced (amiodarone, lithium, interferon-alpha, tyrosine-kinase \\
inhibitors, immune checkpoint inhibitors) \\
\hline Non-thyroidal causes \\
\hline - Physiological increase in elderly people \\
- Severe obesity \\
- Recovery from non-thyroidal illness \\
- Untreated Addison's disease \\
- Assay interferences (heterophilic antibodies, macro TSH) \\
- Thyrotropin resistance (mutation in the TSH-receptor) \\
\hline Transient causes \\
\hline - Autoimmune thyroiditis (silent and post-partum thyroiditis) \\
- Subacute and other forms of thyroiditis \\
- Recovery from non-thyroidal illness \\
- Discontinuation of chronic levothyroxine treatment in euthyroid patients \\
- Post radioiodine therapy to treat Graves' disease \\
- Drug-induced \\
\hline
\end{tabular}


in Table 1 , should also be excluded before considering treatment. Consistently, available guidelines (9-12) have recommended repeating measurements within 3-6 months to exclude laboratory errors or temporary causes of TSH elevation. Only patients with persistent Shypo should be considered for treatment.

\section{CLINICAL SIGNIFICANCE}

Shypo has been categorized into two categories of severity: mild-to-moderate or grade 1 Shypo, when the serum TSH level is between 4.5 and $9.9 \mathrm{mU} / \mathrm{L}$, and more severe or grade 2 Shypo, when serum TSH levels are $\geq 10 \mathrm{mU} / \mathrm{L}$. Grade 2 Shypo patients are more likely to progress to overt hypothyroidism $(\mathrm{OH})$, show symptoms, and develop unfavorable long-term results, and therefore are likely to have more benefits from treatment than those with grade l Shypo $(3,12)$.

\section{Risks of progression to overt hypothyroidism}

It is not completely understood why some patients with Shypo progress to $\mathrm{OH}$, whereas others remain in Shypo or spontaneously regress to euthyroidism. Some individual or populational characteristics appear to influence the natural course of Shypo, such as the iodine level of the population, sex, age, and initial TSH levels (4). There are few population-based studies that evaluated the natural course of Shypo, none in Brazil. In the Whickham cohort (37), the annual progression rate to $\mathrm{OH}$ was greater in individuals with serum TSH levels $>6.0 \mathrm{mU} / \mathrm{L}$ and in the presence of anti-thyroid peroxidase antibody (TPOAb). In a large community study (38), $62 \%$ of the participants had normalized their elevated serum TSH levels in a second determination. Higher TSH levels and positive TPOAb were independently associated with a lower likelihood of reversion to euthyroidism in the elderly, while $\mathrm{TSH} \geq 10$ $\mathrm{mU} / \mathrm{L}$ was independently associated with progression to $\mathrm{OH}(39)$. Prospective studies $(40,41)$ also indicated that the rate of $\mathrm{OH}$ incidence was significantly greater among patients with TSH levels $\geq 10 \mathrm{mU} / \mathrm{L}$ and positive TPOAb. A Brazilian study (42) found that patients with positive thyroid ultrasound aspects of autoimmune thyroiditis were more likely to progress to $\mathrm{OH}$. In conclusion, patients with TSH levels $\geq 10$ $\mathrm{mU} / \mathrm{L}$ and with thyroid autoimmunity have a greater risk of progression to $\mathrm{OH}$.

\section{Quality of life, cognitive function, and depression}

Shypo is associated with no or few clinical manifestations of hypothyroidism, usually unspecific symptoms (1-3). A large population-based study reported significant hypothyroidism-related symptoms in individuals with Shypo compared to those in euthyroidism (43), but other studies have failed to find similar results $(44,45)$. Although a meta-analysis $(46)$ demonstrated a significant relationship between Shypo and cognitive impairment in participants under 75 years of age (but not in those aged 75 or over), another metaanalysis (47) did not find any association. Data on the association of Shypo and depression are also conflicting (48-50). In the elderly, no clear association between Shypo and worsening quality of life, cognitive decline, or depression has been consistently reported (51-57). There are scant RCTs on the benefit of levothyroxine therapy in patients with Shypo. Levothyroxine therapy was associated with a significant improvement of symptoms of tiredness, muscle strength, and quality of life in two small studies $(58,59)$, but another RCT found no relevant benefit to health-related quality of life from 6 months of levothyroxine therapy in women with Shypo (60). Of note, in a recent meta-analysis of 21 studies including 2,192 adults, levothyroxine therapy provided no improvement in quality of life or thyroid-related symptoms (61). Moreover, RCTs have been unable to demonstrate any apparent benefit of treating both older ( $\geq 65$ years) and oldest-old ( $\geq 80$ years) patients with Shypo. (62-64). Thus, there is no clear evidence that the treatment of Shypo is associated with improved quality of life, cognitive function, or depression.

\section{Dyslipidemia}

Thyroid hormones have a marked effect on lipid metabolism, including upregulation of LDL-c receptors and inhibition of LDL-c oxidation (15). Shypo has been associated with increased total cholesterol and LDL-c in small and population-based studies (14), and findings derived from randomized double-blind studies $(58,64-66)$ and meta-analysis $(13,67)$ have shown favorable effects of Shypo treatment on lipid profile. Besides, recent meta-analyses have reported an association between Shypo and endothelial dysfunction (68) with beneficial effects from levothyroxine therapy $(69,70)$. Shypo has also been associated with a higher 
risk of metabolic syndrome, although controversies persist regarding this association (71).

\section{Cardiovascular risk and mortality}

The thyroid hormone regulates the structure and function of the heart through genomic and nongenomic actions with an influence on cardiac growth, myocardial activity, and vascular function (72). A set of heart abnormalities has been associated with both $\mathrm{OH}$ and Shypo, including altered ventricular contractility and relaxation dynamic, compromised cardiac function, and heart failure (HF) $(73,74)$. A mild thyroid hormone deficiency may reduce the entry of calcium into the myocyte, increase the transcription of $\beta$-myosin and decrease that of $\alpha$-myosin, leading to reduced myocyte cell contractile capacity and cardiac atrophy $(19,74)$. This mechanism could partially explain the significant association between Shypo and a greater risk of HF incidence, particularly in patients with $\mathrm{TSH} \geq 10 \mathrm{mU} / \mathrm{L}$ (20) and in the elderly (21). Moreover, Shypo appears to affect the prognosis of patients with $\mathrm{HF}$, increasing the odds of hospitalization and death (75).

The most consistent data on the association of Shypo with cardiovascular risk comes from a metaanalysis (16) including individual data from more than 55,000 participants from 11 prospective studies. The risk of non-fatal CHD events was almost twice as high in participants with grade 2 Shypo compared to those in euthyroidism. Interestingly, the risk of fatal CHD events was about 1.5 times higher in both grade 1 and 2 Shypo. A more recent meta-analysis confirmed these results, especially for younger participants $(\leq 65$ years of age) and individuals at high cardiovascular risk (17). Another meta-analysis of prospective studies associated Shypo with a higher risk of fatal and non-fatal stroke events, but only in younger participants (18). However, the effects of levothyroxine treatment on cardiovascular risk remain doubtful. A recent doubleblind randomized controlled study of 95 participants (mean age, 64 years) with Shypo and acute myocardial infarction failed to find any significant improvement in the left ventricular ejection fraction of patients treated with levothyroxine for 52 weeks (76).

Of note, the detrimental cardiovascular effects of Shypo appear to be well established in younger adults but are less evident in older adults (65-79 years), and even more so in the oldest old ( $\geq 80$ years). In a 4 -year follow-up of octogenarian participants, those with elevated serum TSH levels (up to $10 \mathrm{mU} / \mathrm{L}$ ) were more likely to survive than those with lower TSH values (51). A meta-analysis including 2,531 Shypo participants from 15 studies showed that CHD incidence and cardiovascular/all-cause mortality rates were elevated in those aged 65 and younger, but not in older people (23). Furthermore, a retrospective analysis showed that Shypo patients under 70 treated with levothyroxine faced lower cardiovascular risk than untreated patients, but no benefit was found for those above 70 (77). Thus, Shypo appears to affect young and old people differently. In the elderly, a mild elevation of TSH $(<10$ $\mathrm{mU} / \mathrm{L})$ may reflect a normal age-related increase rather than a thyroid dysfunction $(24,78)$.

\section{TREATMENT}

Although Shypo has been consistently associated with increased cardiovascular risk and mortality, there is lack of evidence on the possible beneficial effect of levothyroxine replacement therapy on these risks $(1-3,27)$. Thus, the decision of whether to treat a patient remains a challenge for clinicians and endocrinologists. Importantly, a recent meta-analysis including 2,192 participants from 21 randomized studies found no benefits in the quality of life or thyroidrelated symptoms of patients with Shypo treated with levothyroxine (61). These findings resulted in a strong recommendation against thyroid hormone therapy in adults with Shypo, except for patients with TSH > 20 $\mathrm{mU} / \mathrm{L}$, with severe symptoms or those under 30 (27). However, this guideline has been contested $(28,29)$. The majority of participants included in the metaanalysis (61) had grade 1 Shypo with mean baseline TSH values ranging from 6.4 to $7.3 \mathrm{mU} / \mathrm{L}$, and at least one-third of them $(\mathrm{n}=737)$ were derived from an RCT study (63) that included elderly patients $\geq 65$ years, in which levothyroxine treatment provided no apparent benefits. Hence, it is not possible to generalize such results to higher-risk patients with grade 2 Shypo, since grade 1 Shypo, particularly in elderly patients, has been not consistently associated with significant clinical consequences (1-3).

In the absence of evidence of any benefits of treating Shypo in patients' clinical manifestations and unfavorable outcomes, the most effective decision-making approach should include a thorough investigation of the patient's condition integrating all relevant clinical data, such as TSH levels, age, quality of life, comorbidities, 
cardiovascular risk, safety, and personal preferences (29). The approach starts with a precise diagnosis in which only patients without non-thyroidal causes of TSH elevation (Table 1) and persistent Shypo should be considered for treatment. The patient's age and the severity of Shypo according to TSH values are the main elements that guide the decision-making process.

\section{Younger patients ( $<65$ years of age)}

The treatment has been recommended for all younger patients with grade 2 Shypo (TSH $\geq 10 \mathrm{mU} / \mathrm{L}$ ) aiming to reduce the risk of progression to $\mathrm{OH}$ and of long-term cardiovascular complications and mortality (Figure 1). Conversely, no treatment is necessary, in general, for healthy and asymptomatic patients with grade 1 Shypo (TSH 4.5-9.9 mU/L) (9-12). However, treatment may be considered for patients with grade l Shypo if serum TSH $\geq 7.0 \mathrm{mU} / \mathrm{L}$, particularly for those with pre-existing cardiovascular disease or high cardiovascular risk, due to the association with a higher risk of fatal and non-fatal CHD and stroke in this context $(3,10,12,16)$. Clinicians can also consider treating patients with grade 1 Shypo at higher risk of progression to $\mathrm{OH}$ (female gender, a progressive increase of TSH levels, positive TPOAb, or US pattern of autoimmune thyroiditis). Moreover, a therapeutic test with levothyroxine for a determined period (at least three months) may be performed in patients with hypothyroidism-related symptoms. If no symptom relief is observed after TSH normalization, treatment should be stopped (Figure 1) (9-12).

\section{Older patients ( $\geq 65$ years of age)}

The clinical approach to elderly patients with Shypo requires even more caution. On the one hand, these patients are less likely to progress to $\mathrm{OH}(39,78)$ and there is no clear evidence of the association of Shypo with worse quality of life, symptoms related to hypothyroidism, cognitive impairment, and depression (51-57), or with unfavorable cardiovascular outcomes $(23,24,51,77)$. Furthermore, no RCT study $(62)$ or meta-analysis (60) has demonstrated a clear benefit of treatment in this subgroup of patients in terms of thyroid-related symptoms, quality of life, and cognition function. Finally, large studies failed to show any significant beneficial effect of levothyroxine therapy in

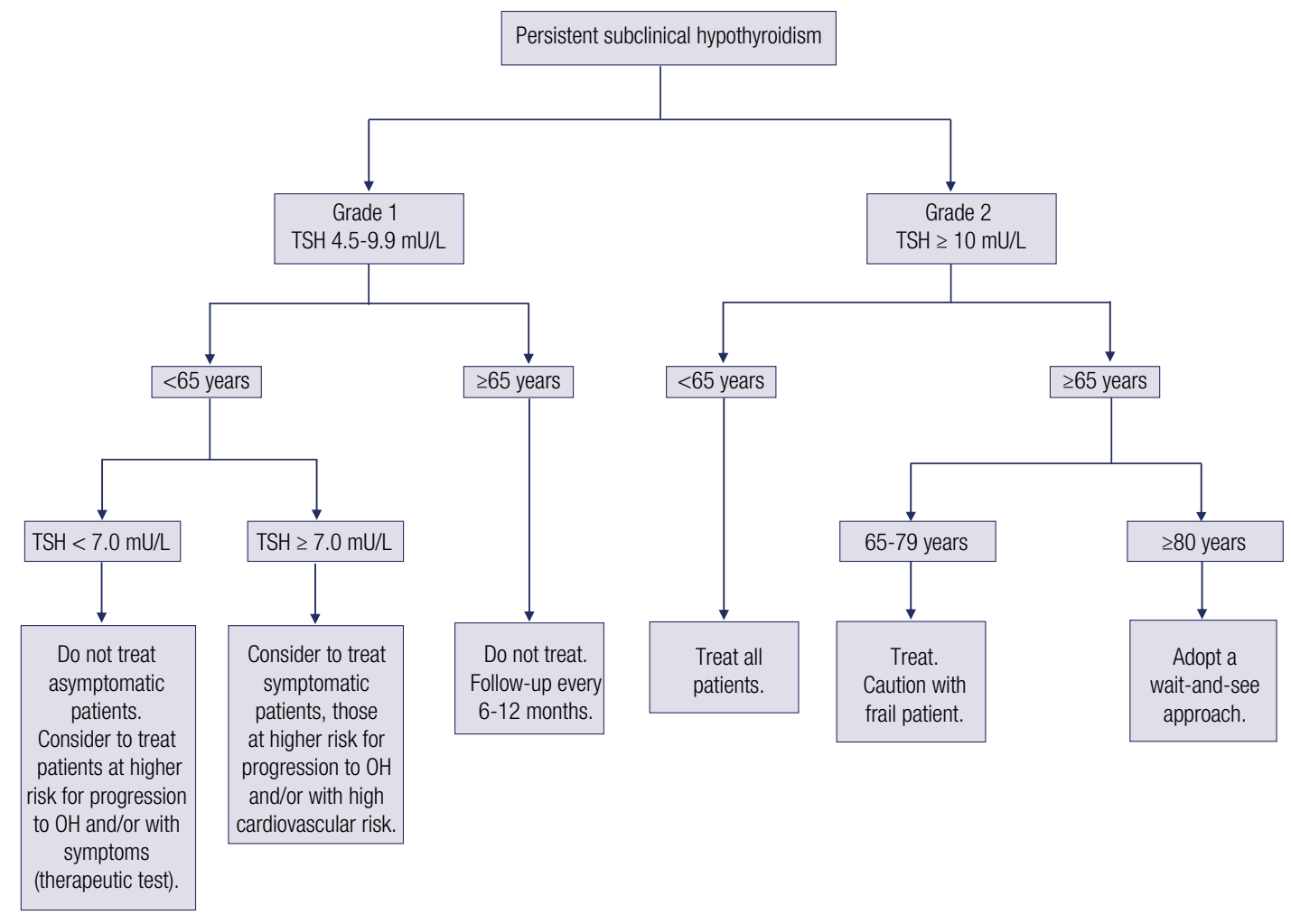

Figure 1. Algorithm for levothyroxine replacement therapy for patients with persistent subclinical hypothyroidism 
older people $>65-79$ years regarding fatal- and nonfatal cardiovascular events and all-cause mortality $(23,77-80)$.

On the other hand, older people are at higher risk of levothyroxine overtreatment and are more susceptible to significant adverse consequences, such as reduction of bone mineral density (81), heart failure (21), and atrial fibrillation $(82,83)$. Of note, a Brazilian multicenter study including 2,292 patients with hypothyroidism found that $14.4 \%$ were using supraphysiological doses of levothyroxine (84). Together, these data reinforce the importance of a decision-making process based on personal contexts and a careful balance between risks and benefits. Guidelines (9-12) have recommended the treatment of Shypo in older patients only when TSH $\geq 10 \mathrm{mU} / \mathrm{L}$, particularly if at a higher cardiovascular risk (Figure 1). However, a wait-and-see approach has been proposed for the oldest old ( $\geq 80$ years of age) $(1,3,12,24)$ and frail patients $(78)$, aiming to avoid levothyroxine therapy because these patients are at higher risk of harmful effects and overtreatment $(1,12,24,77,78)$. Levothyroxine replacement therapy should be considered for this set of patients only when $\mathrm{TSH}$ levels are above $10 \mathrm{mU} / \mathrm{L}$ and there are clear symptoms of hypothyroidism and/or high cardiovascular risk $(1,12,24,78)$.

\section{How to treat}

The treatment of Shypo must follow the same principles as the treatment of $\mathrm{OH}$. In summary, the drug of choice is levothyroxine, and there is no recommendation for combined therapy T4 + T3, particularly in elderly or frail patients. The initial dose varies depending on the patient's context, such as the severity of Shypo, age, and presence of comorbidities, usually no more than $50 \mu \mathrm{g} /$ day. Starting doses of $25 \mu \mathrm{g} /$ day and $12 \mu \mathrm{g} /$ day should be recommended for older (65-79 years) and oldestold ( $\geq 80$ years) patients, respectively, with progressive titration every 4-8 weeks considering optimal TSH target values from 2,5 to $6 \mathrm{mU} / \mathrm{L}(1-3,9,24,78)$.

In conclusion, Shypo is highly prevalent in the general population and increasingly common in medical practice; if not recognized and treated, it can be associated with long-term important complications. However, a screening strategy is still controversial because of the lack of consistent evidence on the benefits of treatment. Therefore, the decision to treat should rely on the available evidence concerning the risks of not treating, on the patient's characteristics, and on individual clinical judgment. A careful individualized approach aiming to identify patients with persistent Shypo who could benefit from levothyroxine therapy is mandatory. Patients under 65 with grade 2 Shypo (TSH $\geq 10 \mathrm{mU} / \mathrm{L}$ ) or with grade 1 Shypo (TSH $>7.0 \mathrm{mU} / \mathrm{L}$ ) in the presence of pre-existing high cardiovascular risk should be treated aiming to reduce long-term cardiovascular complications. Treatment can also be considered in younger patients and grade I Shypo (4.5-9.9 mU/L) at a high risk of progression to $\mathrm{OH}$ or in patients who are symptomatic. However, a more cautious and conservative approach is required in older (65-79 years of age), and oldest-old ( $\geq 80$ years) patients, particularly those with frailty, in which the risk of treatment can outweigh potential benefits.

Disclosure: no potential conflict of interest relevant to this article was reported.

\section{REFERENCES}

1. Cooper DS, Biondi B. Subclinical thyroid disease. Lancet. 2012;379:1142-54.

2. Peeters RP. Subclinical hypothyroidism. $N$ Engl $J$ Med. 2017;376:2556-65.

3. Biondi B, Cappola AR, Cooper DS. Subclinical Hypothyroidism: A Review. JAMA. 2019;322:153-60.

4. Taylor PN, Albrecht D, Scholz A, Gutierrez-Buey G, Lazarus JH, Dayan CM, et al. Global epidemiology of hyperthyroidism and hypothyroidism. Nat Rev Endocrinol. 2018;14:301-16.

5. Hollowell JG, Staehling NW, Flanders WD, Hannon WH, Gunter EW, Spencer CA, et al. Serum TSH, T(4), and thyroid antibodies in the United States population (1988 to 1994): National Health and Nutrition Examination Survey (NHANES III). J Clin Endocrinol Metab. 2002;87:489-99.

6. Madariaga AG, Palacios SS, Guillén-Guima F, Galofré JC. The incidence and prevalence of thyroid dysfunction in Europe: a meta-analysis. J Clin Endocrinol Meta. 2014;99:923-31.

7. Olmos RD, Figueiredo RC, Aquino EM, Lotufo PA, Bensenor IM. Gender, race and socioeconomic influence on diagnosis and treatment of thyroid disorders in the Brazilian Longitudinal Study of Adult Health (ELSA-Brasil). Braz J Med Biol Res. 2015;48:751-8.

8. Sgarbi JA, Matsumura LK, KasamatsuTS, Ferreira SR, Maciel RM. Subclinical thyroid dysfunctions are independent risk factors for mortality in a 7.5-year follow-up: the Japanese-Brazilian thyroid study. Eur J Endocrinol. 2010;162:569-77.

9. Garber JR, Cobin RH, Gharib H, Hennessey JV, Klein I, Mechanick $\mathrm{Jl}$, et al. American Association of Clinical Endocrinologists and American Thyroid Association Task force on Hypothyroidism in Adults. Clinical practice guidelines for hypothyroidism in adults: cosponsored by the American Association of Clinical Endocrinologists and the American Thyroid Association. Thyroid. 2012;22:1200-35.

10. Sgarbi JA, Teixeira PF, Maciel LM, Mazeto GM, Vaisman M, Montenegro Junior RM, et al. The Brazilian consensus for the clinical approach and treatment of subclinical hypothyroidism in adults: recommendations of the thyroid Department of the Brazilian Society of Endocrinology and Metabolism. Arq Bras Endocrinol Metab. 2013;57:166-83. 
11. Brenta G, Vaisman M, Sgarbi JA, Bergoglio LM, Andrada NC, Bravo PP, et al. Clinical practice guidelines for the management of hypothyroidism. Arq Bras Endocrinol Metab. 2013;57:265-91.

12. Pearce SH, Brabant G, Duntas LH, Monzani F, Peeters RP, Razvi S, et al. 2013 ETA Guideline: Management of Subclinical Hypothyroidism. EurThyroid J. 2013;2:215-28.

13. Villar HC, Saconato H, Valente O, Atallah AN. Thyroid hormone replacement for subclinical hypothyroidism. Cochrane Database Syst Rev. 2007;(3):CD003419.

14. Pearce EN. Update in lipid alterations in subclinical hypothyroidism. J Clin Endocrinol Metab. 2012;97:326-33.

15. Duntas LH, Brenta G. A Renewed Focus on the Association Between Thyroid Hormones and Lipid Metabolism. Front Endocrinol (Lausanne). 2018;9:511.

16. Rodondi, N, den Elzen, WP, Bauer DC, Cappola AR, Razvi S, Walsh $\mathrm{JP}$, et al. Subclinical hypothyroidism and the risk of coronary heart disease and mortality. JAMA. 2010;304:1365-74.

17. Moon S, Kim MJ, Yu JM, Yoo HJ, Park YJ. Subclinical hypothyroidism and the risk of cardiovascular disease and allcause mortality: A meta-analysis of prospective cohort studies. Thyroid. 2018;9:1101-10.

18. Chaker L, Baumgartner C, den Elzen WP, Ikram MA, Blum MR, ColletTH, et al. Subclinical Hypothyroidism and the Risk of Stroke Events and Fatal Stroke: An Individual Participant Data Analysis. J Clin Endocrinol Metab. 2015;100:2181-91.

19. Roos A, LinksTP, Wolffenbuttel BH. Subclinical thyroid disease and heart failure. Eur J Heart Fail. 2014;16:119-21.

20. Gencer B, ColletTH, Virgini V, Bauer DC, Gussekloo, J, Cappola AR, et al. Subclinical thyroid dysfunction and the risk of heart failure events: an individual participant data analysis from 6 prospective cohorts. Circulation. 2012;126:1040-6.

21. Nanchen D, Gussekloo J, Westendorp RG, Stott DJ, Jukema JW, Trompet S, et al. Subclinical thyroid dysfunction and the risk of heart failure in older persons at high cardiovascular risk. J Clin Endocrinol Metab. 2012;97:852-61.

22. Rugge JB, Bougatsos $C$, Chou R. Screening and treatment of thyroid dysfunction: an evidence review for the U.S. Preventive Services Task Force. Ann Intern Med. 2015;162:35-45.

23. Razvi S, Shakoor A, Vanderpump M, Weaver JU, Pearce SH. The influence of age on the relationship between subclinical hypothyroidism and ischemic heart disease: a metaanalysis. J Clin Endocrinol Metab. 2008;93:2998-3007.

24. Calsolaro V, Niccolai F, Pasqualetti G, Calabrese AM, Polini A, Okoye $\mathrm{C}$, et al. Overt and Subclinical Hypothyroidism in the Elderly: When to Treat? Front Endocrinol (Lausanne). 2019;10:177.

25. Redford C, Vaidya B. Subclinical hypothyroidism: Should we treat? Post Reprod Health. 2017;23:55-62.

26. Chrysant SG. The current debate over treatment of subclinical hypothyroidism to prevent cardiovascular complications. Int J Clin Pract. 2020;74(7):e13499.

27. Bekkering GE, AgoritsasT Lytvyn L, Heen AF, Feller M, Moutzouri E, et al.Thyroid hormones treatment for subclinical hypothyroidism: a clinical practice guideline. BMJ. 2019;365:I2006.

28. Taylor P, Bianco AC. Urgent need for further research in subclinical hypothyroidism. Nat Rev Endocrinol. 2019;15:503-4.

29. Sawka AM, Cappola AR, Peeters RP, Kopp PA, Bianco AC, Jonklaas J. Patient Context and Thyrotropin Levels Are Important When Considering Treatment of Subclinical Hypothyroidism. Thyroid. 2019;29:1359-63.

30. Brenta G, Caballero AS, Nunes MT. Case finding for hypothyroidism should include type 2 diabetes and metabolic syndrome patients: A Latin American Thyroid Society (LATS) position statement. Endocr Pract. 2019;25(1):101-5.
31. Boucai L, Hollowell JG, Surks MI. An approach for development of age-, gender-, and ethnicity-specific thyrotropin reference limits. Thyroid. 2011;21:5-11.

32. Fontes R, Coeli CR, Aguiar F, Vaisman M. Reference interval of thyroid stimulating hormone and free thyroxine in a reference population over 60 years old and in very old subjects (over 80 years): comparison to young subjects. Thyroid Res. 2013;6(1):13.

33. van Hulsteijn LT, Pasquali R, Casanueva F, Haluzik M, Ledoux $S$ Monteiro MP, et al. Prevalence of endocrine disorders in obese patients: systematic review and meta-analysis. Eur J Endocrinol. 2020;182:11-21.

34. Khan SM, Hamnvik OP, Brinkoetter M, Mantzoros CS. Leptin as a modulator of neuroendocrine function in humans. Yonsei Med J. 2012;53:671-9.

35. Santini F, Marzullo P, Rotondi M, Ceccarini G, Pagano L, Ippolito $S$, et al. Mechanisms in endocrinology: the crosstalk between thyroid gland and adipose tissue: signal integration in health and disease. Eur J Endocrinol. 2014;171:R137-52.

36. Wajner SM, Maia AL. New Insights toward the Acute Non-Thyroidal Illness Syndrome. Front Endocrinol (Lausanne). 2012;3:8.

37. Vanderpump MP, Tunbridge WM, French JM, Appleton D, Bates D, Clark $F$, et al. The incidence of thyroid disorders in the community: a twenty-year follow-up of the Whickhan Survey. Clin Endocrinol (Oxf). 1995;43:55-68.

38. Meyerovitch J, Rotman-Pikielny P, Sherf M, Battat E, LevyY, Surks MI. Serum thyrotropin measurements in the community: fiveyear follow-up in a large network of primary care physicians. Arch Intern Med. 2007;167:1533-8.

39. Somwaru LL, Rariy CM, Arnold AM, Cappola AR. The natural history of subclinical hypothyroidism in the elderly: the cardiovascular health study. J Clin Endocrinol Metab. 2012;97:1962-9.

40. Huber G, Staub JJ, Meier C, Mitrache C, Guglielmetti M, Huber P, et al. Prospective study of the spontaneous course of subclinical hypothyroidism: prognostic value of thyrotropin, thyroid reserve, and thyroid antibodies. J Clin Endocrinol Metab. 2002;87:3221-6.

41. Diez JJ, Iglesias P. Spontaneous subclinical hypothyroidism in patients older than 55 years: an analysis of natural course and risk factors for the development of overt thyroid failure. J Clin Endocrinol Metab. 2004;89:4890-7.

42. Rosário PW, Bessa B, Valadão MM, Purisch S. Natural history of mild subclinical hypothyroidism: prognostic value of ultrasound. Thyroid. 2009;9:9-12.

43. Canaris GJ, Manowitz NR, Mayor G, Ridgway EC. The Colorado thyroid disease prevalence study. Arch Intern Med. 2000;160:526-34.

44. Jorde R, Waterloo K, Storhaug H, Nyrnes A, Sundsfjord J, Jenssen TG. Neuropsychological function and symptoms in subjects with subclinical hypothyroidism and the effect of thyroxine treatment. J Clin Endocrinol Metab. 2006;91:145-53.

45. Roberts LM, Pattison H, Roalfe A, Franklyn J, Wilson S, Hobbs FD, et al. Is subclinical thyroid dysfunction in the elderly associated with depression or cognitive dysfunction? Ann Int Med. 2006;145:573-81.

46. Pasqualetti G, Pagano G, Rengo G, Ferrara N, Monzani F. Subclinical Hypothyroidism and Cognitive Impairment: Systematic Review and Meta-Analysis. J Clin Endocrinol Metab. 2015;100:4240-8.

47. Rieben C, Segna D, da Costa BR, Collet TH, Chaker L, Aubert CE, et al. Subclinical Thyroid Dysfunction and the Risk of Cognitive Decline: a Meta-Analysis of Prospective Cohort Studies. J Clin Endocrinol Metab. 2016;101:4945-54

48. Tang R, Wang J, Yang L, Ding X, Zhong Y, Pan J, et al. Subclinical Hypothyroidism and Depression: A Systematic Review and MetaAnalysis. Front Endocrinol (Lausanne). 2019;10:340.

49. Loh HH, Lim LL, Yee A, Loh HS. Association between subclinical hypothyroidism and depression: an updated systematic review and meta-analysis. BMC Psychiatry. 2019:19(1):12. 
50. Zhao T, Chen BM, Zhao XM, Shan ZY. Subclinical hypothyroidism and depression: a meta-analysis. Transl Psychiatry. 2018;8:239.

51. Gussekloo J, van Exel E, de Craen AJ, Meinders AE, Frölich M, Westendorp RG. Thyroid status, disability and cognitive function, and survival in old age. JAMA. 2004;292:2591-9.

52. Formiga F, Ferrer A, Padros G, Contra A, Corbella X, Pujol R; Octabaix Study Group. Thyroid status and functional and cognitive status at baseline and survival after 3 years of followup: the OCTABAIX study. Eur J Endocrinol. 2013;170:69-75.

53. Tognini S, Pasqualetti G, Calsolaro V, Polini A, Monzani F. Cognitive function and quality of life in mild thyroid hormone deficiency. Recent Pat Endocr Metab Immune Drug Discov. 2014;8:124-34.

54. Parsaik AK, Singh B, Roberts RO, Pankratz S, Edwards KK, Geda $\mathrm{YE}$, et al. Hypothyroidism and risk of mild cognitive impairment in elderly persons: a population-based study. JAMA Neurol. 2014;71:201-7.

55. Akintola AA, Jansen SW, van Bodegom D, van der Grond J, Westendorp RG, de Craen AJ, et al. Subclinical hypothyroidism and cognitive function in people over 60 years: a systematic review and meta-analysis. Front Aging Neurosci. 2015;7:150.

56. Blum MR, Wijsman LW, Virgini VS, Bauer DC, den Elzen WP, Jukema JW, et al.; PROSPER study group. Subclinical thyroid dysfunction and depressive symptom among the elderly. Neuroendocrinology. 2016;103:291-9.

57. McCahon D, Haque MS, Parle J, Hobbs FR, Roberts LM. Subclinical thyroid dysfunction symptoms in older adults: cross-sectional study in UK primary care. Br J Gen Pract. 2020;70:e208-14.

58. Kong WM, Sheikh MH, Lumb PJ, Naoumova RP, Freedman DB, Crook M, et al. A 6-month randomized trial of thyroxine treatment in women with mild subclinical hypothyroidism. Am J Med. 2002;112:348-54.

59. Razvi S, Ingoe L, Keeka G, Oates C, McMillan C, Weaver JU. The beneficial effect of L-thyroxine on cardiovascular risk factors, endothelial function, and quality of life in subclinical hypothyroidism: randomized, crossover trial. J Clin Endocrinol Metab. 2007;92:1715-23.

60. Reuters VS, Almeida Cde P, Teixeira Pde F, Vigário Pdos S, Ferreira $\mathrm{MM}$, Castro $\mathrm{CL}$, et al. Effects of subclinical hypothyroidism treatment on psychiatric symptoms, muscular complaints, and quality of life. Arq Bras Endocrinol Metabol. 2012;56:128-36.

61. Feller M, Snel M, Moutzouri E, Bauer DC, de Montmollin M, Aujesky D, et al. Association of Thyroid Hormone Therapy with Quality of Life and Thyroid-Related Symptoms in Patients with Subclinical Hypothyroidism: A Systematic Review and Metaanalysis. JAMA. 2018;320:1349-59.

62. Parle J, Roberts L, Wilson S, Pattison H, Roalfe A, Haque MS, et al. A randomized controlled trial of the effect of thyroxine replacement on cognitive function in community-living elderly subjects with subclinical hypothyroidism: the Birmingham Elderly Thyroid Study. J Clin Endocrinol Metab. 2010;95:3623-32.

63. Stott DJ, Rodondi N, Kearney PM, Ford I, Westendorp RGJ, Mooijaart SP, et al. Thyroid HormoneTherapy for Older Adults with Subclinical Hypothyroidism. N Engl J Med. 2017;376:2534-44.

64. Mooijaart SP, Du Puy RS, Stott DJ, Kearney PM, Rodondi N, Westendorp RGJ, et al. Association Between Levothyroxine Treatment and Thyroid-Related Symptoms Among Adults Aged 80 Years and Older with Subclinical Hypothyroidism. JAMA. 2019;322:1-11.

65. Monzani F, Caraccio N, Kozàkowà M, Dardano A, Vittone F, Virdis $A$, et al. Effect of levothyroxine replacement on lipid profile and intima-media thickness in subclinical hypothyroidism: a double-blind, placebo-controlled study. J Clin Endocrinol Metab. 2004;89:2099-106.

66. Teixeira Pde F, Reuters VS, Ferreira MM, Almeida CP, Reis FA, Buescu $A$, et al. Lipid profile in different degrees of hypothyroidism and effects of levothyroxine replacement in mild thyroid failure. Transl Res. 2008;151:224-31.

67. Li X, Wang Y, Guan Q, Zhao J, Gao L. The lipid-lowering effect of levothyroxine in patients with subclinical hypothyroidism: A systematic review and meta-analysis of randomized controlled trials. Clin Endocrinol. 2017;1:1-9.

68. Gong N, Gao C, Chen X, Fang Y, Tian L. Endothelial Function in Patients with Subclinical Hypothyroidism: A Meta-Analysis. Horm Metab Res. 2019;51:691-702.

69. Aziz M, Kandimalla Y, Machavarapu A, Saxena A, Das S, Younus A, et al. Effect of Thyroxin Treatment on Carotid IntimaMedia Thickness (CIMT) Reduction in Patients with Subclinical Hypothyroidism (SCH): a Meta-Analysis of Clinical Trials. J AtherosclerThromb. 2017;24:643-59.

70. Zhao T, Chen B, Zhou Y, Wang X, Zhang Y, Wang H, et al. Effect of levothyroxine on the progression of carotid intima-media thickness in subclinical hypothyroidism patients: a meta-analysis. BMJ Open. 2017;7(10):e016053.

71. Iwen KA, Oelkrug R, Kalscheuer H, Brabant G. Metabolic Syndrome in Thyroid Disease. Front Horm Res. 2018;49:48-66.

72. Razvi S, Jabbar A, Pingitore A, Danzi S, Biondi B, Klein I, et al. Thyroid Hormones and Cardiovascular Function and Diseases. $J$ Am Coll Cardiol. 2018;71:1781-96.

73. Bielecka-Dabrowa A, Godoy B, Suzuki T, Banach M, von Haehling S. Subclinical hypothyroidism and the development of heart failure: an overview of risk and effects on cardiac function. Clin Res Cardiol. 2019;108:225-33.

74. Biondi B. Mechanisms in endocrinology: Heart failure and thyroid dysfunction. Eur J Endocrinol. 2012;167:609-18.

75. Yang G, Wang Y, Ma A, Wang T. Subclinical thyroid dysfunction is associated with adverse prognosis in heart failure patients with reduced ejection fraction. BMC Cardiovasc Disord. 2019;19(1):83.

76. Jabbar A, Ingoe L, Junejo S, Carey P, Addison C, Thomas H, et al. Effect of Levothyroxine on Left Ventricular Ejection Fraction in Patients with Subclinical Hypothyroidism and Acute Myocardial Infarction: A Randomized Clinical Trial. JAMA. 2020;324:249-58.

77. Razvi S, Weaver JU, ButlerTJ, Pearce SH. Levothyroxine treatment of subclinical hypothyroidism, fatal and nonfatal cardiovascular events, and mortality. Arch Intern Med. 2012;172:811-7.

78. Ruggeri RM, Trimarchi F, Biondi B. Management of Endocrine Disease: I-Thyroxine replacement therapy in the frail elderly: a challenge in clinical practice. Eur J Endocrinol. 2017;177(4):R199217.

79. Andersen MN, Olsen AM, Madsen JC, Faber J, Torp-Pedersen C, Gislason GH, et al. Levothyroxine Substitution in Patients with Subclinical Hypothyroidism and the Risk of Myocardial Infarction and Mortality. PLoS One. 2015;10(6):e0129793.

80. Andersen MN, Olsen AS, Madsen JC, Kristensen SL, Faber J, TorpPedersen C, et al. Long-Term Outcome in Levothyroxine Treated Patients with Subclinical Hypothyroidism and Concomitant Heart Disease. J Clin Endocrinol Metab. 2016;101:4170-7.

81. Blum MR, Bauer DC, ColletTH, Fink HA, Cappola AR, da Costa BR, et al. Subclinical thyroid dysfunction and fracture risk: a metaanalysis. JAMA. 2015;313:2055-65.

82. Sawin CT, Geller A, Wolf PA, Belanger AJ, Baker E, Bacharach P, et al. Low serum thyrotropin concentrations as a risk factor for atrial fibrillation in older persons. N Engl J Med. 1994;331:1249-52.

83. Cappola AR, Fried LP, Arnold AM, Danese MD, Kuller LH, Burke GL, et al.Thyroid status, cardiovascular risk, and mortality in older adults. JAMA. 2006;295:1033-41.

84. Vaisman F, Coeli CM, Ward LS, Graf H, Carvalho G, Montenegro $\mathrm{R} \mathrm{Jr}$, et al. How good is the levothyroxine replacement in primary hypothyroidism patients in Brazil? Data of a multicentre study. J Endocrinol Invest. 2013;36:485-8. 